\title{
Combustion Characteristics of Nanoparticle Laden Butanol
}

\author{
Gaurav Mittal, Jasmeet Kalra
}

\begin{abstract}
Combustion characteristics of fuels can be improved by addition of nanoparticles. In this work, fuels prepared by adding Aluminium and Iron nanopowders into butanol as well as a nanoparticle laden fuel, prepared by laser ablation, are studied. Three types of experiments are conducted, namely, (i) burning of suspended droplets to understand the effect of nano-particle type and concentration on burning rate behavior (ii) ignition of fuel droplets on a heated plate and (iii) the energy density measurements using an oxygen bomb calorimeter. The enhancement of combustion properties and distinct features of nanofuel combustion are discussed.
\end{abstract}

Keywords: nanofuel, droplet combustion, hot plate ignition, energy density

\section{INTRODUCTION}

The low energy density $(<43 \mathrm{MJ} / \mathrm{Kg}$ ) of non-petroleum based fuels contributes to a barrier to their commercial success, particularly for high speed propulsion. Addition of high energy nanoparticles in fuels provides a pathway to increase the combustion efficiency, enhance power output and potentially reduce greenhouse emissions. In addition, nanoparticle laden fuels are characterized by faster ignition time scales, high rate of energy release and reliable ignition under extremely lean conditions [1-6]. These characteristics of high energy density and reaction rates are highly desirable for advanced high-speed propulsion systems that could exploit nanofuels.

In addition, nanoparticle generation by laser ablation in liquids has proven to be an efficient technique to generate charged nanoparticles that exhibit colloidal stability. This novel processing technique eliminates handling of nanomaterials and produces stable colloidal suspensions that do not require any further process steps or additives. The purpose of this work was to evaluate the combustion performance of the nanoparticle laden fuels. Butanol was the base fuel for combustion measurements and experiments were conducted for fuels prepared by mixing nano-powders ( $\mathrm{Al}$ and $\mathrm{Fe}$ ) into butanol using $0.5 \mathrm{wt} \%$ Span 80 as well as for fuel prepared using laser ablation. Three types of experiments were conducted - (1) Burning of suspended droplets (2) Ignition of fuel droplets on a heated plate and (3) The energy density measurements using a calorimeter. In the following, the details of the experiments and the results are discussed.

\section{SUSPENDED DROPLET IGNITION}

Burning characteristics of 1-2 $\mathrm{mm}$ diameter suspended droplets were investigated to understand the effect of nanoparticles on burning rate and burning behavior. The droplets were stabilized on beads ( $200 \mu \mathrm{m}$ diameter) on quartz fibers placed inside a closed transparent chamber of volume $0.25 \mathrm{~m}^{3}$. The schematic of the experiment is shown in Fig. 1. The suspended droplets were ignited using a spark discharge through two stainless steel electrode wires positioned near the droplet. The ignition energy for the spark was provided by discharging an automotive coil, saturated through a constant current power supply (GW Instek GPR $1810 \mathrm{HD}$ ), through a $10 \mu \mathrm{F}$ capacitor. It was recognized that a single spark was seldom sufficient to ignite the droplet. Therefore, a labview program was written to control the relay in the ignition circuit which afforded a number of consecutive sparks separated by a short time interval. This program also synchronized the ignition relay with a solenoid that was used to withdraw the spark electrodes after ignition. Typically, eight consecutive sparks, separated by $7 \mathrm{~ms}$ time interval, were used to ignite the droplets and the electrodes were withdrawn immediately after the last spark.The burning droplets were imaged using a high speed camera (Photron Fastcam SA 3) with intense backlight from a flashlight for droplet diameter determination and weak backlight for imaging of flame and particle burning. The images were recorded at $1000 \mathrm{fps}$ with a spatial resolution of $\sim 10 \mu \mathrm{m} /$ pixel by using a $50 \mathrm{~mm}$ Nikon lens and an extension tube.

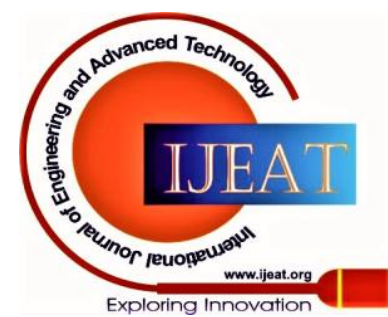






Fig. 1- Schematic of the suspended droplet ignition experiment

Fig. 2A shows snapshots of burning sequence for butanol, 2B, 2C \& 2E exhibit $\mathrm{Al}$ and $\mathrm{Fe}$ nano-fuels prepared by mixing nano-particles with butanol and $2 \mathrm{D}$ exhibits $\mathrm{Al}$ nano-fuel synthesized by laser processing. As expected, butanol showed smooth burning without any droplet disruption and follows the $\mathrm{D}^{2}$ burning law, as shown in Figs. 3 and 2A. Figure 3 also shows that butanol containing $\mathrm{Al}$ nano-particles deviated from the $\mathrm{D}^{2}$ law at $\mathrm{D}^{2} / \mathrm{D}_{\mathrm{o}}{ }^{2}$ ratios between 0.4 and 0.6. Both Fe and $\mathrm{Al}$ nano-fuels exhibited steady burning in the initial combustion stage. After the initial stage, the droplet size decreased to a critical value where droplet disruption occurs. In the disruption phase, droplets and particles were ejected from the primary droplet. The particle trajectory basically followed the direction of the ejected droplets. 


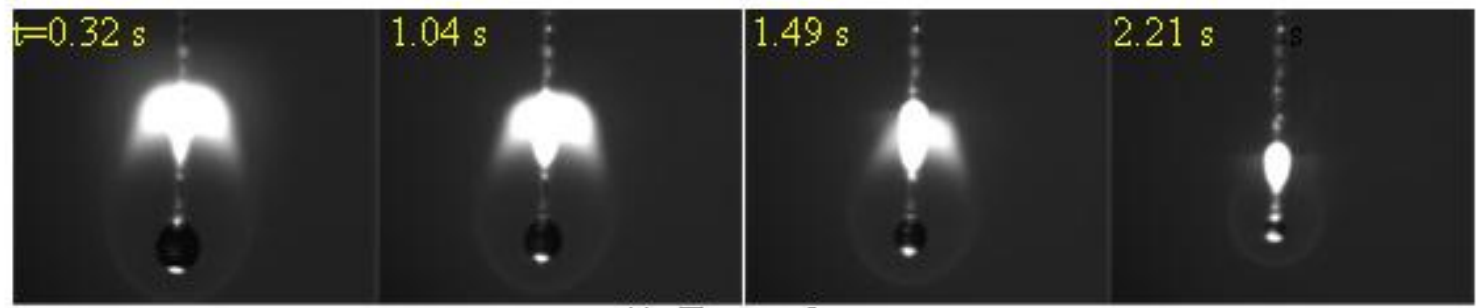

\section{A) Butanol}
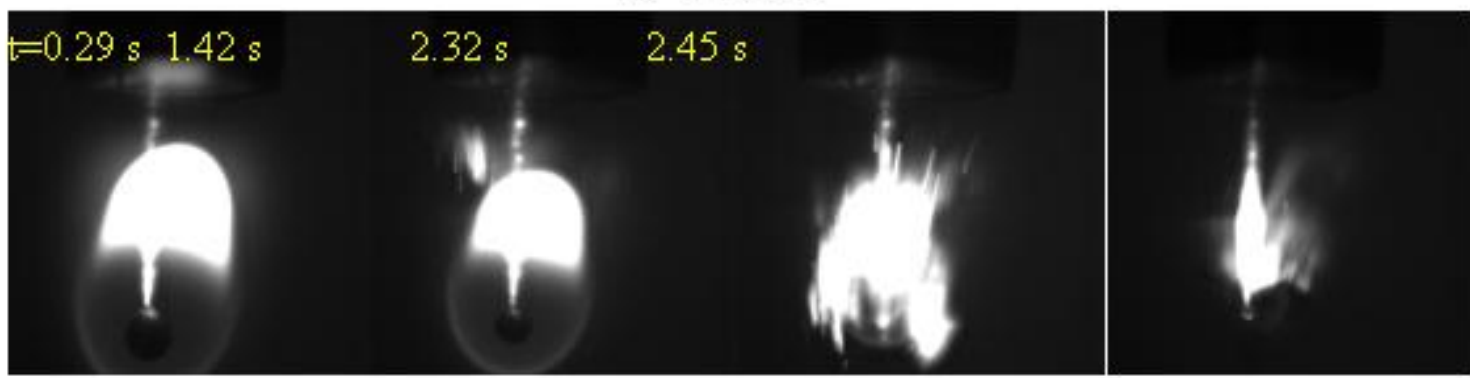

Steady Flame

Particle Streaks

Intense Distuption

Clear Bead Near End

B) Butanol +1 v $\% \mathrm{Al}$
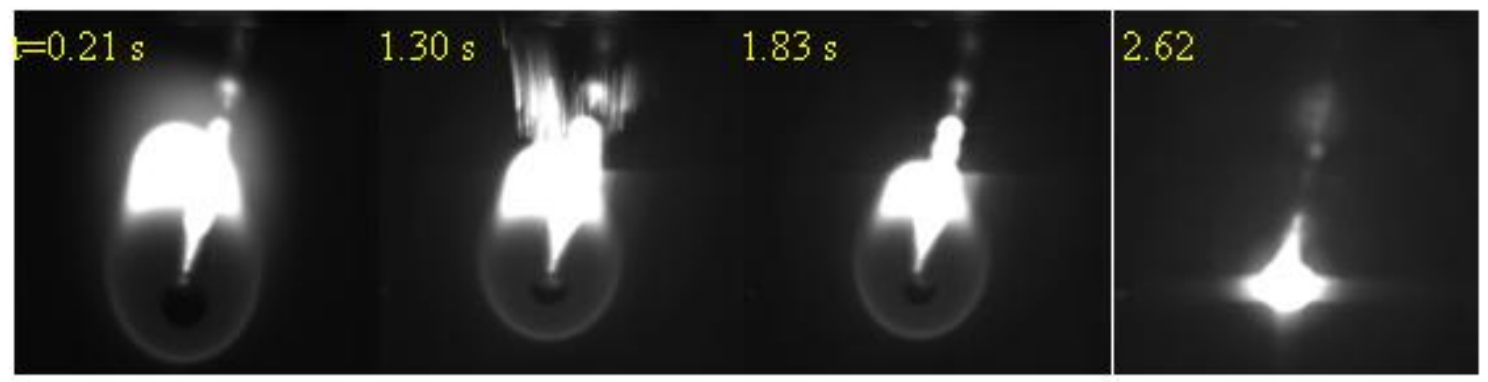

Steady Flame

Particle Streaks

Steady Flame

A1 Burning on Bead

C) Butanol $+2.5 \mathrm{v} \% \mathrm{Al}$



Steady Flame

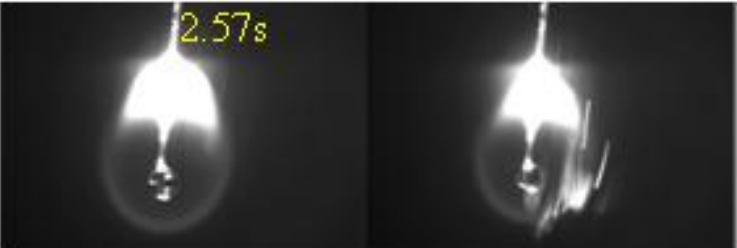

Steady Flame

Particle Streaks

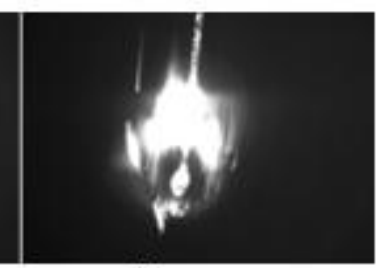

Intense

D) Laser - Butanol $+0.02 \mathrm{v} \% \mathrm{Al}$



Steady Flame
Particle Streaks
Intense Distuption
E) Butanol $+5 \mathrm{v} \% \mathrm{Fe}$

Near End

Fig 2-Burning sequence of fuel droplets: A) butanol, B) $1 \mathrm{v} \% \mathrm{Al}$, C) $25 \mathrm{v} \% \mathrm{Al}$, D) laser and $\mathrm{E}$ ) $5 \mathrm{v} \% \mathrm{Fe}$

Both ejected droplets and particles were subsequently burned as they entered the hot zone of the primary droplet. The burning particles are visible as streak lines in Fig. 2 . More particles were ignited as the droplet size became smaller. In the final stage, butanol and $\mathrm{Al}$ particles were consumed leaving no residue on the quartz bead. It should

be noted that after the disruption stage for $2.5 \mathrm{v} \% \mathrm{Al}$, steady burn behavior was restored and the final stage resulted in burning of dry agglomerated $\mathrm{Al}$ particles on the quartz bead.
The burning sequence of $5 \quad \mathrm{v} \% \quad \mathrm{Fe} \quad$ exhibited considerably stronger

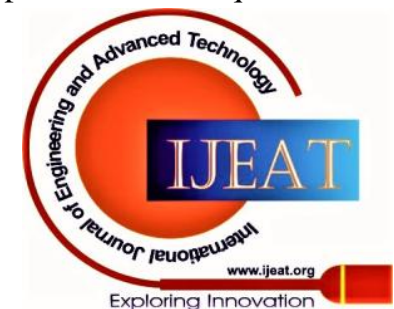


disruption and micro-explosion behavior. The time scale for droplet ignition and combustion was shorter than $\mathrm{Al}$. Fe particles burned in the primary droplet flame, leaving almost no residue on the quartz bead. Soot reduction was also observed for $\mathrm{Fe}$ addition; the results showed a decrease in soot luminosity. This effect could be due to less soot production or enhanced soot oxidation rate in the presence of Fe nano-particles.

The disruption and micro-explosion behavior of the nano-fuel was attributed to pressure build-up inside the droplet due to local superheating. The difference in the combustion behavior with nano-particle type and concentration was due to the difference in nano-particle agglomeration behavior. At relatively lower Al concentration (1 v\%), Al particles and butanol burned simultaneously. The higher Al concentration (2.5 v\%) burned in a 'sequential' manner, where the Al agglomerate combusts after depletion of butanol. Simultaneous combustion behavior yielded higher energy release rate and possibly better combustion by avoiding $\mathrm{Al}$ agglomerates. In contrast, Fe exhibited simultaneous combustion behavior at $5 \mathrm{v} \%$.

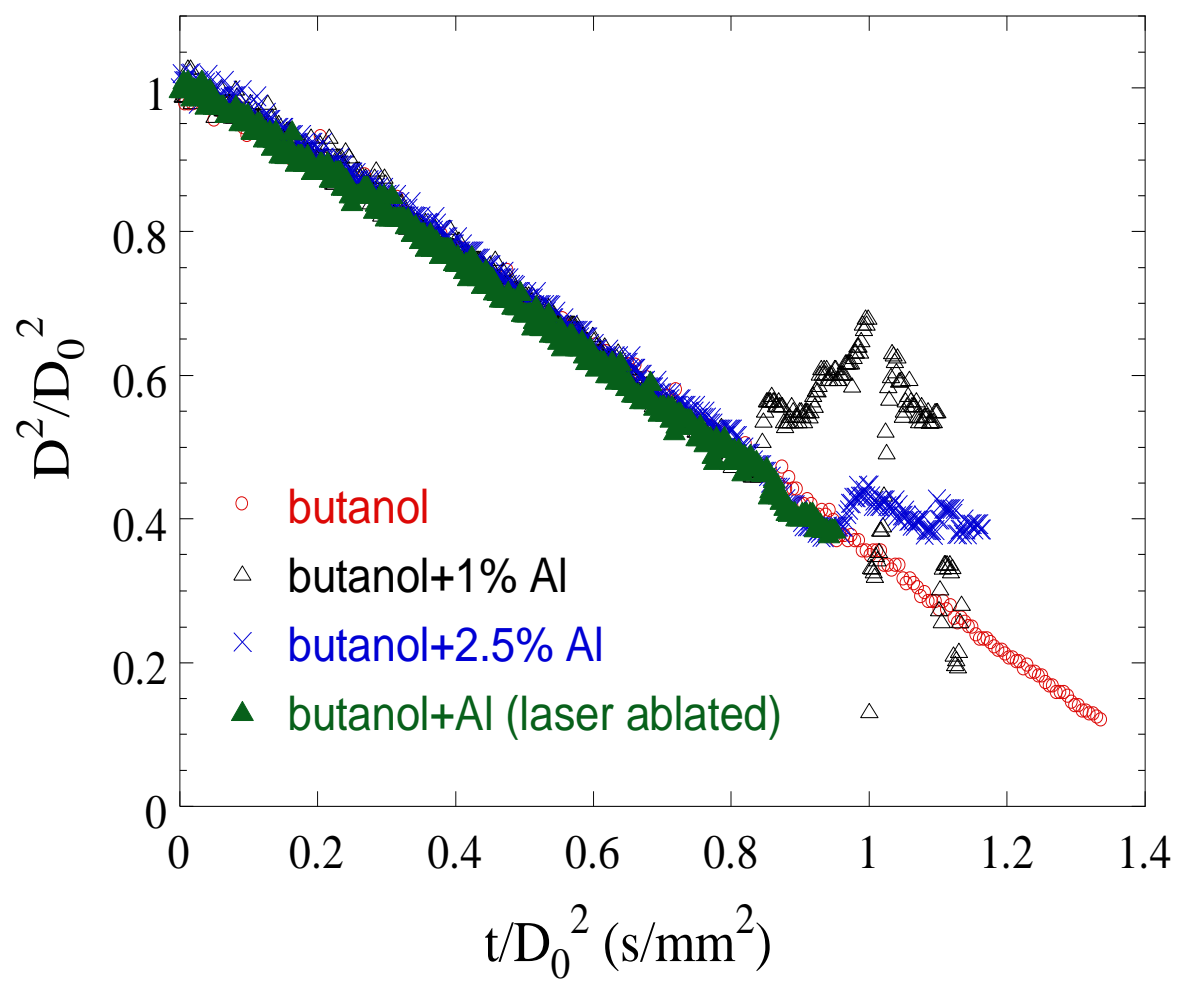

Fig. 3 - Droplet diameter history

\section{HOT PLATE IGNITION}

Ignition of fuel droplets was also investigated on a stainless steel plate heated up to $760{ }^{\circ} \mathrm{C}$. The experiments were conducted under a fume hood. The schematic is shown in Fig. 4. The stainless steel plate ( $1 / 2$ inch thick, 5 inch diameter) was placed directly above an electric heater made of nichrome wire arranged in a serpentine fashion on refractory cement and insulated from sides and bottom. The power supply to the nichrome wire was regulated using a variac which allowed temperature control of the plate. A concave depression was machined on the top surface of the plate and polished with a fine grit emery paper to ensure that the droplet did not move off the plate surface. Two holes machined radially in the plate at 1 and $3 \mathrm{~mm}$ below the top surface allowed placement of $\mathrm{K}$ type thermocouples and precise determination of temperature at the center of the plate. The droplets of $\sim 1.7 \mathrm{~mm}$ radius were dropped in the center of the plate by using a pipette from a height of $20 \mathrm{~mm}$ and ignition was observed visually. 


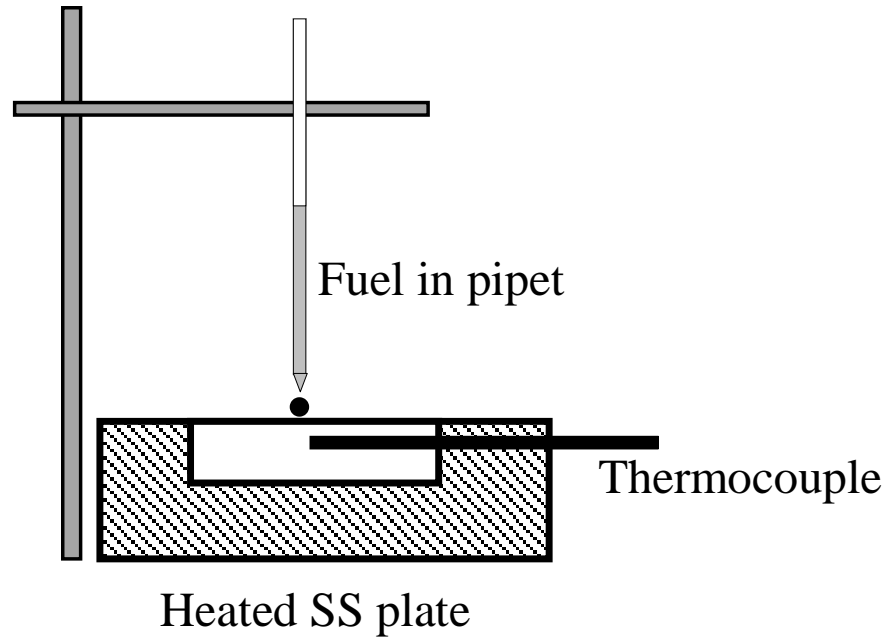

Fig. 4 - Schematic of the hot plate ignition experiment

At temperatures above the Leidenfrost temperature, the droplet floats on the heated plate and receives heat by convection and radiation. The experiments showed that 2.5 v\% Al droplets ignited at $660{ }^{\circ} \mathrm{C}$, whereas pure butanol ignition occurred at temperatures greater than $690{ }^{\circ} \mathrm{C}$. The lower ignition temperature with nano-particles is probably due to enhanced thermal conductivity and radiation absorption. An interesting observation was that at hot plate temperatures above $370{ }^{\circ} \mathrm{C}$ even though the droplets did not ignite, the $\mathrm{Al}$ agglomerate left after the evaporation of butanol did ignite. The temperature of $370{ }^{\circ} \mathrm{C}$ is significantly below the melting point of $\mathrm{Al}\left(657{ }^{\circ} \mathrm{C}\right)$. Typically, micron size $\mathrm{Al}$ particles require temperatures greater than $1400{ }^{\circ} \mathrm{C}$ to ignite due to the presence of the oxide layer. Al nano-particle addition offers an advantage by depressing the fuel ignition temperature.

\section{ENERGY DENSITY}

The energy density was measured by using an oxygen bomb calorimeter (Parr 1341 Plane Jacket Calorimeter with Parr 1108 Combustion Bomb). The calorimeter was calibrated and used in accordance with ASTM D240. The following volumetric energy density was measured for butanol and butanol/Al fuels: 1) butanol-29.89 MJ/L, 2) $1 \mathrm{v} \%$ Al-30.33 $\mathrm{MJ} / \mathrm{L}$ and 3) $2.5 \mathrm{v} \% \mathrm{Al}-31.24 \mathrm{MJ} / \mathrm{L}$. A $4.5 \%$ increase in energy density is observed using $\mathrm{Al}$ nano-particles.

\section{CONCLUDING REMARKS}

Combustion characteristics of butanol laden with $\mathrm{Al}$ and $\mathrm{Fe}$ nanoparticles were studied. Both $\mathrm{Fe}$ and $\mathrm{Al}$ nano-fuels exhibited steady burning in the initial stage. However, droplet disruption occurred at a critical diameter. The burning of $5 \mathrm{v} \% \mathrm{Fe}$ manifested considerably stronger disruption and micro-explosion behavior. Furthermore, $\mathrm{Fe}$ particles left almost no residue on the quartz bead. For low $\mathrm{Al}$ concentration $(1 \mathrm{v} \%)$, Al particles and butanol burned simultaneously, whereas at higher Al concentration (2.5 v\%) they burned in a 'sequential' manner. The hot plate ignition experiments showed that $2.5 \mathrm{v} \% \mathrm{Al}$ droplets ignited at 660 ${ }^{\circ} \mathrm{C}$, whereas pure butanol ignition occurred at temperatures greater than $690{ }^{\circ} \mathrm{C}$. In addition, $4.5 \%$ increase in energy density was observed using $2.5 \mathrm{v} \% \mathrm{Al}$ nano-particles.

\section{REFERENCES}

1. K.K. Kuo, G.A. Risha, B.J. Evans, E. Boyer, in:Materials Research Society Fall Meeting, 2003,Paper No. AA1.1.

2. G.V. Ivanov, F. Tepper, in: K.K. Kuo, T.B. Brill,R.A. PesceRodriguez, et al. (Eds.), Challenges inPropellants and Combustion: 100 Years After Nobel,Begell House, New York, 1997, pp. 636-645.

3. A. Rai, K. Park, L. Zhou, M.R. Zachariah,Combustion Theory and Modelling 10 (5) (2006) 843-859.

4. C. Allen, G. Mittal, C.J. Sung, E. Toulson, T. Lee, Proceedings of the Combustion Institute 33 (2011) 3367-3374

5. S. Tanvir, L. Qiao, Nanoscale Research Letters volume 7, Article number: 226 (2012)

6. D. Sundaram, V. Yang. R.A. Yetter, Progress in Energy and Combustion Science 61 (2017) 293-365 